\title{
Is Pakistan on track to have COVID-19 transmission and mortality rates similar to those of Italy, Iran or the USA?
}

\author{
Bilal Javed $^{1,2}\left(\right.$ D $\cdot$ Abdullah Sarwer $^{3,4} \cdot$ Erik B. Soto $^{5} \cdot$ Zia-ur-Rehman Mashwani $^{1}$
}

Published online: 15 April 2020

(c) Springer Nature Switzerland AG 2020

\section{The novel Coronavirus SARS-CoV-2}

The first case of infection with a novel coronavirus was reported in Wuhan, China, in late December 2019. The virus is zoonotic in nature, spreading through human-animal interactions, with the wet seafood markets of Wuhan being considered the breeding grounds of this coronavirus. Initially, the virus was called the Wuhan virus, the bat virus, and 2019-nCoV. On 11 February 2020, after rising in notoriety because of its rapid transmission and dire impact on morbidity and mortality rates, the virus was given the taxonomic nomenclature of "severe acute respiratory syndrome coronavirus 2 (SARS-CoV-2)" by the World Health Organization (WHO); the disease it causes is known as COVID-19 [1]. The first genome sequence of SARS-CoV-2 was submitted on 12 January 2020 to the US National Center of Biotechnology's database with ID NC_045512. It showed that SARS-CoV-2 is a 29,903 bp (base pairs) single-stranded RNA coronavirus, with a close resemblance to SARS-CoV and MARS-CoV [2].

Scientific, medical, and governmental communities across the world continue to work together to find ways of preventing, treating, or managing COVID-19:

Bilal Javed

javedbila187@gmail.com; javedb@sas.upenn.edu

1 Faculty of Sciences, PMAS-Arid Agriculture University, Rawalpindi, Punjab 46300, Pakistan

2 Roy and Diana Vagelos Laboratories, Department of Chemistry, University of Pennsylvania, Philadelphia 19104-6323, PA, USA

3 Nawaz Sharif Medical College, University of Gujrat, Gujrat, Punjab 50700, Pakistan

4 Allama Iqbal Memorial Teaching Hospital, Sialkot, Punjab 51310, Pakistan

5 Graduate School of Public Health, University of Pittsburgh, Pittsburgh 15261, PA, USA
- Baig et al. [1] provided evidence of the entry of SARS$\mathrm{CoV}-2$ into cells through the angiotensin-converting enzyme 2 (ACE-2) receptor.

- Zhu et al. [3] identified SARS-CoV-2 as a novel coronavirus causing a pneumonia-like infection in humans.

- Wang et al. [4] explained the epidemiological and clinical features of the emerging COVID-19.

- Fan et al. [5] provided clinical evidence that angiotension-converting enzyme-2 (ACE2) expression in the kidneys and testis can damage kidneys and testis in COVID19-infected patients.

- Andersen et al. [6] determined the proximal origin of SARS-CoV-2.

- van Doremalen et al. [7] explained the aerosol and surface stability of SARS-CoV-2.

\section{Travelers gave SARS-CoV-2 wings}

After the dreadful outbreak in Wuhan, China, and scientific evidence of human-to-human transmission of SARS-CoV-2, governments across the world, most notably the USA, began placing and enforcing travel restrictions to and from China in an effort to stem the reach and spread of the virus. However, initially, as it was a new and relatively unknown virus for which there was lack of screening and testing equipment, SARS-CoV-2 spread rapidly across the world [2]. Indeed, it spread so rapidly that, by 26 February 2020 , the number of new cases of COVID-19 outside of China increased 13-fold compared with those inside China, and the number of countries with cases of COVID-19 had tripled. On 11 March 2020, the WHO categorized COVID-19 as a pandemic [8]. On 27 February 2020, Pakistan reported its first two patients with COVID-19, both of whom had recently returned to Pakistan from Iran [9].

As of 7 March 2020, the global number of confirmed COVID-19 cases surpassed 100,000 (21,110 outside of China, including 4747 in Iran and seven in Pakistan), with 
3073 fatalities (413 outside of China, including 121 in Iran) [10]. In Pakistan, all reported cases were because of direct travel from Iran. By 23 March 2020, the number of WHOconfirmed cases more than tripled to 334,981 , and the number of deaths increased almost fivefold to 14,652 across 190 countries [9] (Fig. 1).

\section{Response of Pakistan's government}

China, an epicenter of COVID-19, is located northeast of Pakistan; Iran, where the number of cases and deaths is increasing exponentially, is located southwest. The extremely severe COVID-19 outbreaks in these two
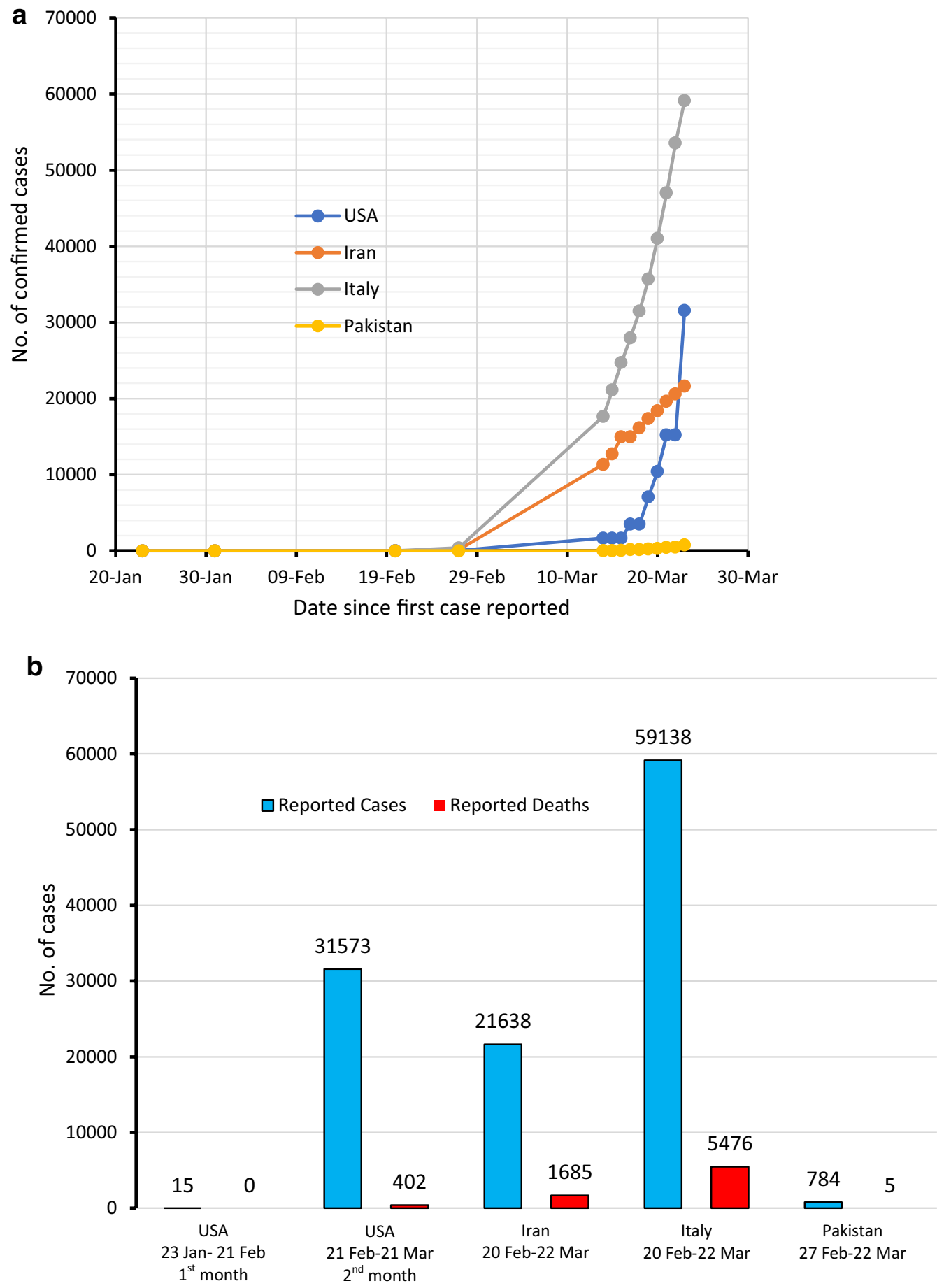

Fig. 1 a Increase in the number of COVID-19 cases since its first outbreak and b month-by-month increase in COVID-19 transmission and death 
bordering countries, in addition to the WHO declaration that COVID-19 is a pandemic, forced Pakistan's government to take swift, drastic, and severe actions to stop the further transmission of SARS-CoV-2 [11]. Notwithstanding this, current trade agreements with China and the politicoreligious relationship with Iran has resulted in an influx of SARS-CoV-2-infected individuals from these two regional epicenters. To curtail further transmission, as a first-line response, Pakistan closed the border with China and initiated very strict screening at the Pakistani-Iranian border. Additionally, in coordination with the civil aviation authority, the government of Pakistan enforced the screening of passengers before they were allowed to enter the country [12].

However, in the earlier days of the pandemic, Pakistan lacked the ability to diagnose COVID-19 directly and relied on China, Japan, and the Netherlands to test their samples. This wasted crucial time and delayed the government's ability to respond adequately to the virus. Fortunately, the government eventually received diagnostic kits from China and primers from Japan to enable their own testing of samples [13].

The WHO designated seven Pakistani hospitals to test patients with suspected COVID-19. Pakistan's federal government, with collaboration from the Ministry of Health, prepared "The National Action Plan for The Corona Virus Disease (COVID-19) Pakistan" to guide provincial governments and states across Pakistan in developing methods and strategies to best deal with the COVID-19 outbreak [12].

Using this guidance, provincial governments established quarantine centers at exposition centers in Lahore and Karachi (two of Pakistan's largest cities) with the help of Pakistan's armed forces. Quarantine centers were established in Sukkur (2000 beds in a newly constructed apartment building), Taftan (located by the Pakistani-Iranian border to identify and quarantine individuals returning to Pakistan from Iran), and Islamabad (very modern center with 300 beds). The government also ordered the closure of all hotels and, invoking special powers, designated some of them as quarantine centers. As well as these containment facilities, the government also established isolation wards in many hospitals [14].

The Ministry of Health also managed to provide crucial supplies, such as face masks, gloves, and protective suits, to protect the paramedical staff and doctors at the frontlines of this pandemic. Hospitals started primarily dealing with crucial emergencies and patients with COVID-19. Telephone helplines were established by provincial governments for people to inquire about COVID-19-related healthcare issues and to inform callers that they should stay at home if they experienced any symptoms of the virus. Campaigns were launched throughout the nation's traditional media and social media outlets to increase awareness among the general public [12].
However, even with all of these efforts, major lapses existed at every step, ranging from inconsistent immigration policies dealing with the influx of people from the borders and airports to the lack of crucial protective suits and other supplies in hospitals. Consequently, the lack of facilities, poor infrastructure, inconsistent governmental policies, and the politico-religious situation resulted in the rapid and continuous spread of COVID-19 throughout the country.

Hospital staff protested against working without adequate protective supplies. Moreover, quarantine centers spread SARS-CoV-2 rather than isolating infected individuals from the healthy populace. The "one room one person" policy was badly neglected, and clean bathrooms and drinking water were lacking. Five people were reported to be living in one single containment room. Whereas the government shifted COVID-19-infected individuals directly to Multan and Faisalabad (large Pakistani urban centers) after changing some of the public university dormitories to quarantine centers in these cities [15].

Hoarding and black-market trade in protective goods to the public resulted in a lack of protective supplies for the country's healthcare practitioners. To mitigate this issue, the National Disaster Management Authority and the Drug Regulation Authority stepped into help the government prevent hoarding and the black market trade of protective supplies [10].

\section{Public response}

The initial response of the public to the emerging threat of COVID-19 was apathy. Lack of awareness was commonplace throughout the country, and mass prayer events continued despite warnings that such public activities would exacerbate the spread of SARS-CoV-2. Social media and other sources spread fear, rumors, and false "facts". The price of common utilities quickly grew with the severing of international trade in an attempt to hamper the spread of the virus, black-market trade in essential goods, and hoarding of many products. Fear of a national economic downturn in an already troubled economy, coupled with the fear of a decline in jobs and in the ability of the average citizen to earn and provide for their families, further hampered the government's ability to lockdown cities and markets. Ordinary citizens ignored governmental calls and ordinances urging people to stay at home to curtail the transmission of the virus. Inconsistent immigration policies at the borders, improper screening, poor quarantine camps, lack of protective supplies, poorly trained healthcare professionals, and the actions of local gangs contributed to the inability to contain the COVID-19 outbreak in Pakistan [16].

A person traveling from Spain evaded the airport screening booth after testing positive, resulting in transmission of 
COVID-19 to his family and community. Moreover, some people at the Sukkur camp broke their quarantine by leaving their rooms and coming into direct contact with others, further spreading the disease [17]. The indifference and noncooperative attitude displayed by the general public further fueled the rapid transmission of COVID-19 across Pakistan.

\section{Current situation in Pakistan}

Less than a month after the first two COVID-19 cases in Pakistan were reported in late February, 784 cases ( 392fold increase) and five deaths in Pakistan were reported by the WHO. Italy and Iran also had a large surge in transmission and deaths during the first month after the first cases (Fig. 1a). Conversely, the number of cases in the USA increased to just 15 in the first month after they reported their first infection. A comparison of WHO-reported data from Pakistan, the USA, Italy, and Iran (Fig. 1b) suggests that Pakistan may be the next country to see an exponential rise in rates of COVID-19 transmission and death [9].

In Pakistan, the biological community have volunteered to help health professionals perform diagnostic tests, such as polymerase chain reaction (PCR). Scientific teams from the National University of Science and Technology and the University of Punjab separately developed low-cost diagnostic kits that will be manufactured in Pakistan, thereby saving time and money. Dr. Shamsi, head of the National Institute of Blood Diseases, has advocated for the use of passive immunization, a medical technique that involves the administration of antibodies from a cured patient to a nonimmune individual, used when a risk of infection is high, the time for the human body to generate an immune response is low, and no vaccine is available [18].

The current COVID-19 situation requires politicians, religious clerics, health professionals, scientists, and the general community to band together to take steps to fight this pandemic. It is generally regarded that the USA, Italy, and Iran have better healthcare systems than Pakistan. Nevertheless, these countries have failed drastically to contain the virus, largely because of inconsistent policies and late decisions and actions. Their failures should prompt the Pakistan government to make and enforce timely decisions to prevent further transmission of the disease. Otherwise, because of the currently limited healthcare facilities and poor infrastructure, the COVID-19 outbreak in Pakistan may soon mirror the situations in Iran and Italy.

\section{Take home messages}

- Beware that the COVID-19 pandemic threatens to collapse healthcare systems worldwide, and its transmission must be stopped.
- Provide the public with information about the severity, transmission, and prevention of COVID-19.

- Encourage public cooperation with government policies to overcome this pandemic.

- Petition governments to develop long-term policies and procedures to better handle such outbreaks, so that an efficient and effective response can be made for any existential threats to the population such as those posed by a virulent outbreak.

Author contributions BJ devised the study, collected and analyzed the data, and wrote the first draft. EBS edited and revised the manuscript. AS and ZRM contributed to subsequent drafts. The authors reviewed and endorsed the final submission.

\section{Compliance with ethical standards}

Conflicts of interest BJ, AS, EBS, and ZM have no conflicts of interest that are directly relevant to the content of this article.

Funding No sources of funding were used to conduct this study or prepare this manuscript.

\section{References}

1. Baig AM, Khaleeq A, Ali U, et al. Evidence of the COVID-19 virus targeting the CNS: tissue distribution, host-virus interaction, and proposed neurotropic mechanisms. ACS Chem Neurosci. 2020. https://doi.org/10.1021/acschemneuro.0c00122 (Epub 2020 Mar 13).

2. Wuhan seafood market pneumonia virus isolate Wuhan-Hu-1, complete genome. Nucleotide, National Center for Biotechnology Information (NCBI), National Library of Medicine (US), National Center for Biotechnology Information, Bethesda, MD. https://www.ncbi.nlm.nih.gov/nuccore/1798174254. Accessed 25 Mar 2020.

3. Zhu N, Zhang D, Wang W, et al. A novel coronavirus from patients with pneumonia in China, 2019. N Engl J Med. 2020;382(8):727-33.

4. Wang Y, Wang Y, Chen Y, et al. Unique epidemiological and clinical features of the emerging 2019 novel coronavirus pneumonia (COVID-19) implicate special control measures. J Med Virol. 2020. https://doi.org/10.1002/jmv.25748 (Epub 2020 Mar 5).

5. Fan C, Li K, Ding Y, et al. ACE2 expression in kidney and testis may cause kidney and testis damage after 2019-nCoV infection. medRxiv. 2020. https://doi.org/10.1101/2020.02.12.20022418.

6. Andersen KG, Rambaut A, Lipkin WI, et al. The proximal origin of SARS-CoV-2. Virological. http://virological.org/t/the-proxi mal-origin-of-sars-cov-2/398. (Epub 2020 Feb 17).

7. van Doremalen N, Bushmaker T, Morris DH, et al. Aerosol and surface stability of SARS-CoV-2 as compared with SARS-CoV-1. N Engl J Med. 2020. https://doi.org/10.1056/NEJMc2004973.

8. World Health Organization (WHO). Coronavirus disease (COVID-19) press briefings [media releases]. https://www.who. int/emergencies/diseases/novel-coronavirus-2019/media-resou rces/press-briefings. Accessed 23 Mar 2020.

9. Hageman JR. The coronavirus disease 2019 (COVID-19) WHO situation report. Pediatr Ann. 2020;49(3):e99-100. 
10. Saqlain M, Muddasir M, Ali M, et al. Is Pakistan prepared to tackle the coronavirus epidemic? Drugs Ther Perspect. 2020;36(5):213-4.

11. Xu J, Yijun C, Hao C, et al. 2019 novel coronavirus outbreak: a quiz or final exam? Front Med. 2020. https://doi.org/10.1007/ s11684-020-0753-1.

12. Pakistan National Institute of Health. National action plan for corona virus disease (COVID-19). https://www.nih.org.pk. Accessed 23 Mar 2020.

13. Pakistan now equipped to test for novel coronavirus, says PM's aide [media release]. https://www.dawn.com/news/1532077. Accessed 24 Mar 2020.

14. Aljazzera News. Coronavirus: inside Pakistan's Taftan quarantine camp [media release]. 2020. https://www.aljazeera.com/progr ammes/newsfeed/2020/03/coronavirus-pakistan-taftan-quarantine -camp-200323110255493.html. Accessed 23 Mar 2020.

15. The International News. 1,270 corona suspects arriving from Iran shifted to Multan quarantine centre [media release]. 2020. https:// www.thenews.com.pk/print/632265-1-270-corona-suspects-arriv ing-from-iran-shifted-to-multan-quarantine-centre. Accessed 23 Mar 2020.

16. Gulf News. Pakistan's first coronavirus death exposes nation's vulnerability [media release]. 2020. https://gulfnews.com/world/ asia/pakistan/pakistans-first-coronavirus-death-exposes-nationsvulnerability-1.70566930. Accessed 25 Mar 2020.

17. ARY News. Coronavirus patients, suspects break out of Sukkur quarantine facility [media release]. 2020. https://arynews.tv/en/ sukkur-quarantine-facility-coronavirus-suspects/. Accessed 23 Mar 2020.

18. The Express Tribune. 'Passive immunisation' can save COVID-19 patients: Pakistan's top hematologist [media release]. 2020. https ://tribune.com.pk/story/2179772/1-passive-immunisation-cansave-covid-19-patients-pakistans-top-hematologist/. Accessed 25 Mar 2020. 